\title{
Relações literárias de Alexandre Herculano com a cultura letrada brasileira
}

\author{
Literary relations between Alexandre Herculano and Brazilian lettered \\ culture \\ Hugo Lenes MENEZES* \\ Instituto Federal de Educação, Ciência e Tecnologia do Piauí (IFPI)
}

\begin{abstract}
RESUMO: O diálogo da cultura escrita do Brasil com a do exterior é acentuado. Aqui a arte verbal é um legado do colonizador europeu. Por isto, nossas manifestações literárias iniciais são encaradas como ressonâncias das metrópoles. Este fato origina uma interessante terminologia, a luso-brasileira, que é utilizada na classificação de um grupo de obras publicadas por autores portugueses que moram na Colônia durante a tutela do império lusitano. Alguns deles, como o Padre Antônio Vieira e Tomás Antônio Gonzaga, muito se identificam com nossos valores e são considerados integrantes de um patrimônio comum aos dois países. Embora tal diálogo diminua depois de uma maior penetração da civilização francesa no século XIX, Brasil e Portugal continuam parceiros. Assim sendo, no presente artigo, abordamos o lusitano Alexandre Herculano em suas relações com nossa cultura letrada.
\end{abstract}

PALAVRAS-CHAVE: Alexandre Herculano. Relações literárias. Portugal. Brasil.

ABSTRACT: There is a strong dialogue between foreign countries and Brazilian lettered culture. In Brazil, the verbal art is a legacy of the European colonizers. Therefore, our initial literary manifestations are seen as resonances of the metropolis. This fact leads to an interesting terminology, the Luso-Brazilian, which is used in the classification of a group of works published by Portuguese authors who lived in the Brazilian colony during the Portuguese Empire. Some of them, like the Padre Antônio Vieira and Tomás Antônio Gonzaga, identify themselves a lot with Brazil's values and are considered members of a common heritage that belongs to both Brazil and Portugal. Although such dialogue decreases after a greater influence of the French civilization in the nineteenth-century Brazil, Brazil and Portugal remain partners. Therefore, in this article, we discuss the Portuguese writer Alexandre Herculano and its relations with Brazilian lettered culture.

KEYWORDS: Alexandre Herculano. Literary relations. Portugal. Brazil.

\footnotetext{
* Doutor em Teoria e História Literária pela Universidade Estadual de Campinas (UNICAMP), com PósDoutorado em Estudos Comparados de Literaturas em Língua Portuguesa pela Universidade de São Paulo (USP) e Aperfeiçoamento pelo Centre d'Approches Vivantes des Langues et des Médias (CAVILAM), de Vichy, França. Professor Titular do Departamento de Ciências Humanas e Letras do IFPI. E-mail: hugomenezes@ifpi.edu.br
} 
Convencionalmente, localizamos o início do Romantismo luso na publicação em Paris de Camões (1825), poema de Almeida Garrett, que apresenta da estética em foco a exaltação de um herói nacional, a recuperação patriótica da liberdade e os versos brancos, numa obra que não teve sequência imediata nas letras vernáculas, pois, somente após a volta dos exilados, é que observamos a continuidade de um novo estilo de época. Ademais, os versos do poema garrettiano em questão têm ainda um sabor neoclássico. Até porque a vocação romântica do Solitário de Vale de Lobos manifestase, à primeira vista, mais tardiamente que a de Almeida Garrett, o qual, de resto, é onze anos mais velho do que seu irmão de armas. De onde, certamente, o caso de Alexandre Herculano ter se libertado melhor do Classicismo e de seu lugar na história do Romantismo lusitano se faz mais claro que o de Almeida Garrett.

Por consequência, para António José Saraiva e Óscar Lopes em História da literatura portuguesa (1955), é preferível marcar tal início, mais exatamente, quando vem a lume, em conformidade com Palavras de um crente (1834), de Félicité de Lamennais, a prosa poética de Alexandre Herculano intitulada $A$ voz do profeta (1836), folheto o qual, mais do que pelo teor político, faz sucesso pelo estilo, denunciando a vitória, em Portugal, da nova estética. Igualmente, no Brasil, como vamos demonstrar, é público e notório o sucesso da presença intelectual do autor em epígrafe, que conta aqui com numerosos leitores, especialmente em meio aos principais literatos oitocentistas (Gonçalves Dias, Bernardo Guimarães, Gonçalves de Magalhães, José de Alencar, Machado de Assis, entre outros), e a quem em 1861 o Gabinete Português de Leitura do Rio de Janeiro concede o título de presidente honorário da instituição, além de elegê-lo, em 1875, sócio do Instituto Histórico e Geográfico Brasileiro.

Isto posto, começamos por dizer que Alexandre Herculano, em "O futuro literário de Portugal e do Brasil", empreende, sobre Primeiros cantos (1846), de Gonçalves Dias, crítica elogiosa. Portanto, não nos surpreende o fato de o bardo maranhense reimprimir semelhante obra, em 1857, com toda a publicação anterior, transcrevendo o artigo herculaniano no prólogo. "Neste, o poeta brasileiro declara a satisfação e honra em merecer algumas linhas daquele escritor famoso e de muitos leitores" (MALARD, 1995, p. 29). Do mesmo modo, o professor de literatura lusobrasileira e literatura judaico-brasileira da Universidade Brown, nos Estados Unidos, e 
autor de Brasil e Portugal: a imagem recíproca, de 1991, Nelson H. Vieira recorda-se de Alexandre Herculano na condição do articulista de

"Futuro literário de Portugal e do Brasil", artigo aparecido primeiramente na Revista Universal Lisbonense e, mais tarde, na $3^{\mathrm{a}}$ edição de Primeiros cantos: coleção de poesias (Brockhaus: Leipzig, 1857), escrito pelo poeta brasileiro Gonçalves Dias. Este artigo louva a poesia do vate maranhense e o progresso literário brasileiro. O historiador português refere-se ao Brasil como $o$ mercado principal do pouco que entre nós se imprime. Procedendo assim, ele atesta a popularidade da literatura portuguesa no Brasil. (VIEIRA, 1991, p. 85)

No que concerne à parte histórico-ficcional da novelística de Alexandre Herculano, na década de 1840, ele se realiza plenamente com os romances $O$ monge de Cister, Eurico, o presbítero e $O$ bobo, ${ }^{1}$ num desfile de séculos, do VIII ao XV, em que busca reconstituir sociológica e psicologicamente o clima da Idade Média, suas crenças e valores. E sobre a repercussão de tais livros junto ao público luso-brasileiro, Soares Amora realça que os dois romances de Alexandre Herculano acerca da vida dos monges
medievais - Eurico, o presbítero e $O$ monge de Cister - impuseram-se, de
imediato, como obras de escândalo (pela tese que desenvolviam do conflito,
sem solução, entre os votos sacerdotais e os impulsos veementes da natureza
humana), e daí como obras ampla e profundamente difundidas em todas as
camadas de leitores de Portugal e do Brasil. Popularidade igual só
alcançaram, depois, O Guarani (1857), de José de Alencar, As pupilas do
senhor reitor (1867), de Júlio Dinis, O crime do padre Amaro (1875), de Eça
de Queirós, e Dom Casmurro (1899), de Machado de Assis. (AMORA, s.d.,
p. 5-6) O romance medievalista herculaniano que não possui como tema nuclear os conflitos internos dos representantes do viver monacal, qual seja, $O$ bobo, igualmente conhece uma bem sucedida recepção tanto no país de origem quanto no Brasil. Pertinentemente, Josué Montello observa que:

$O$ bobo apareceu em livro, pela primeira vez, numa contrafação brasileira. Sinal de que, atentos aos méritos do escritor, tivemos a primazia de reconhecer que este romance histórico não podia ficar limitado ao domínio de uma publicação periódica e que o livro correspondia ao seu horizonte natural. No rolar do tempo, se mudaram as modas literárias e o gosto do grande público, $O$ bobo não deixou de ter aquele número de leitores fiéis que lhe assegura sucessivas reedições. (MONTELLO, s.d., p. 6)

\footnotetext{
${ }^{1} O$ monge de Cister é publicado parcialmente em $O$ Panorama em 1841 e, em volume, em 1848; Eurico, o presbitero é parcialmente publicado em $O$ Panorama e na Revista Universal Lisbonense em 1843 e, em volume, em 1844; $O$ bobo é publicado em $O$ Panorama em 1843 e, em volume, postumamente, em 1878, tendo circulado também, em vida do autor, numa edição pirata brasileira, de 1866. $O$ monge de Cister e Eurico, o presbítero constituem o Monasticon, título geral que Alexandre Herculano confere a um ciclo de romances históricos (que afinal fica em díptico), versando sobre a insubmissão das paixões à disciplina eclesiástica.
} 
Em terras brasílicas, o romance romântico O seminarista (1872), escrito por Bernardo Guimarães, dialoga com as narrativas históricas que integram o Monasticon. Particularmente, entre Eurico, o presbítero e $O$ seminarista, em nível temático, são muitos os pontos de aproximação, como a tirania paterna em relação ao casamento dos filhos, o anticlericalismo, o amor sacrílego, a sublimação do amor profano no divino, a divisão do ser humano entre as leis dos desejos pessoais e as leis sociais, a morte e a loucura por amor.

Inclusive, em $O$ seminarista, Bernardo Guimarães empreende uma retomada, com menos poesia, do esquema final de Alexandre Herculano em Eurico, o presbítero: "a loucura do Padre Eugênio após a violação de suas promessas religiosas lembra a morte do presbítero e a demência de Hermengarda" (BOSI, 1981, p. 158). Entretanto, tal narrativa bernardiana, cognominada "o Eurico brasileiro" por Dilermando Cruz, citado por Antonio Candido (1993, p. 216), acentua, numa presença tangível da carne, os traços da sensualidade tolhida, do instinto reprimido pelo voto de castidade, o que Alexandre Herculano não faz. Acerca deste aspecto, Karin Volubuef ressalta um parecer do estudioso estadunidense Norwood Andrews, o qual postula, no ensaio intitulado " $O$ seminarista, de Bernardo Guimarães - romance de transição", que o ficcionista brasileiro mostra o tormento do protagonista Eugênio como um problema meramente biológico. Vejamos:

O pesquisador compara o dilema do celibato em Bernardo Guimarães e em
Alexandre Herculano: no autor português, o amor seria espiritual e a quebra
dos votos de castidade implicaria um problema ético; já no autor brasileiro, o
amor configura-se como um imperativo carnal, como necessidade do corpo, e
ceder a ele seria abandonar-se aos ditames da Natureza, contrariando a lei dos
homens, que é claramente antinatural. Dali para frente, Andrews passa a
apontar para a volúpia que impregna as descrições de Margarida e para o
apelo sexual que isto tem para o rapaz seminarista. (VOLUBUEF, 1999, p.
306)

Destarte, o escritor mineiro antecipa-se à problemática do romance $O$ missionário (1888), de autoria de um dos principais representantes do Naturalismo brasileiro: Inglês de Sousa. Por conseguinte, O seminarista, como indica Antonio Candido, "situa-se não apenas cronológica, mas ideologicamente entre a obra de Herculano e $O$ crime do Padre Amaro (1875), de Eça de Queirós" (1993, p. 216). E a exemplo do que destaca Marisa Lajolo sobre o encaixe narrativo de uma obra brasileira escrita por um amigo íntimo de Bernardo Guimarães, qual seja, Noite da taverna 
(1855), de Álvares de Azevedo, no Portugal da primeira metade do século XIX o conto "A dama pé-de-cabra", integrante de Lendas e narrativas (1851), de Alexandre Herculano, encena "a restauração da aliança primitiva entre narrador e ouvintes, comunitariamente reunidos, de que fala Walter Benjamin” (LAJOLO, 1991, p. 118).

Em vernáculo, a arte de contar, da qual se revela um mestre Bernardo Guimarães, também autor de Lendas e romances (1871), obra inspirada em Lendas e narrativas (1851), de Alexandre Herculano, encontra um marco inolvidável na coletânea intitulada Contos do tio Joaquim (1861), do prosador lusitano Rodrigo Paganino. Esta coletânea atinge, em especial junto à massa de leitores anônimos, várias edições até os dias de hoje, decerto pela identificação de tal obra com a tradição oral, que comumente se mantém viva em meio ao grande público, de onde,

\begin{abstract}
Partindo da ideia de que, "entre nós, nestes últimos tempos sobretudo, a literatura tem desprezado um tanto o gosto popular", e amparado no exemplo de Émile Souvestre e seu Au coin du feu (Ao pé do fogo, 1852), como reconhece e declara, o ficcionista imagina um tio Joaquim meio bíblico, que "nunca soube ler", a despender os serões da aldeia narrando histórias perpassadas duma sentimentalidade fácil, melodramática, via de regra acerca do namoro, e duma religiosidade ingênita, supersticiosa, emblematizada no dito popular "voz do povo é a voz de Deus", dando origem a uma evidente ou implícita moralidade cristã, que por pouco não nos faz regressar aos “exemplos” de Trancoso. (MOISÉS, 1999, p.15-16)
\end{abstract}

Neste sentido, boa parte do êxito alcançado por Bernardo Guimarães deve-se ao fato de ele, em sua prosa de ficção, nunca ter abandonado a postura de narrador verbal de histórias folclóricas à beira do fogo, nas fazendas ou humildes moradias do campo, demonstrando habilidade para tocar viola e intercalar as narrativas com canções. Assim sendo, com a transposição do narrador oral para a produção folhetinesca (contos, novelas e romances) de Bernardo Guimarães, julgamos viável identificá-lo com o jogral da Idade Média, ${ }^{2}$ tão bem reconstituída por Alexandre Herculano, e identificar os leitores com a plateia, o que podemos constatar, por exemplo, em "A cabeça de Tiradentes", de Histórias e tradições da província de Minas Gerais (1872). Nesta obra, o narrador, como o faz o da herculaniana narrativa "A dama pé-de-cabra", se declara contador de histórias, chegando a simular uma situação de oralidade. Vejamos:

\footnotetext{
${ }^{2}$ Todo aquele que, na condição de trovador ou intérprete musical e literário, bem como de mímico, acrobata, etc., divertia o público. Cf. MOISÉS, M. Jogral. In: Dicionário de termos literários. São Paulo: Cultrix, 1997. p. 297.
} 
Quereis, minhas senhoras, que vos conte uma história para disfarçar o enfado destas longas e frigidíssimas noites de maio? [...] E, pois, vou contar-vos a história de uma caveira memorável. Não se arrepiem, minhas senhoras; não é histórias de almas do outro mundo, de trasgos, nem de duendes. É uma simples tradição nacional, ainda bem recente, e da nossa própria terra. (GUIMARÃES, 1976, p. 3-4. Grifos nossos)

Como vemos, o narrador bernardiano encarna mesmo o típico contador de histórias. Este é dono de certo fascínio ao se expressar, senhor de um discurso repositório de provérbios, de casos, ou "causos", os quais, constituindo uma forma simples, se afinam com nosso povo. ${ }^{3}$ Entendemos semelhante dado como digno de consideração, visto que, por seu intermédio, se resgata a aludida representação benjaminiana da tradição oral e comunitária, enquanto lugar de troca de vivências, na esteira de um medievalista como Alexandre Herculano, tradição esta que o ambiente interiorano, de transformações mais lentas, conserva sob a condição de memória coletiva. ${ }^{4}$ Aqui, o rito narrativo denota a associação entre oralidade e escrita, habitual na cultura da Idade Média, quando os textos possuem uma destinação, sobretudo, oral. Em tal direção, noutra narrativa bernardiana de Histórias e tradições da província de Minas Gerais, "A filha do fazendeiro", a voz enunciativa também recorre à expressão contar história. Depois de mostrar uma fazenda largada no sertão mineiro, com uma ermida próxima a um túmulo, o sujeito textual faz esta provocação:

Se o leitor deseja saber que acontecimentos deram lugar ao abandono daquela linda fazenda, e qual o mistério que encerram aquela sepultura e aquela capelinha, leia a seguinte história, que há tempos me foi contada por um morador daquelas paragens, e que eu tratarei de reproduzir com toda a fidelidade e individuação, que a memória me permitir. (GUIMARÃES, 1976, p. 17. Grifos nossos)

No presente contexto, o narrador herculaniano, numa das mais antigas páginas da ficção portuguesa, isto é, a mencionada lenda "A dama pé-de-cabra", assume, sem subterfúgio, que reconta (e assim recupera) uma tradição, numa fidelidade intencional ao velho modo ingênuo e espontâneo dos relatos folclóricos perante uma assembleia.

\footnotetext{
${ }^{3}$ Além do caso, nas formas simples, são incluídos o mito, a lenda, a saga, a adivinha, o ditado, o memorável, o conto e o chiste. Ver JOLLES, A. Formas simples. São Paulo: Cultrix, 1997.

${ }^{4}$ Igualmente, o enredo do romance-folhetim $O$ ermitão de Muquém (1869), de Bernardo Guimarães, apresenta-se como narrado durante quatro pousadas, quatro conversas antes de dormir, ou serões, ao redor da fogueira, por um companheiro de viagem, nos acampamentos de tropa ao ar livre. Nestes casos, a separação e extensão dos capítulos propendem a representar as diversas sessões do relato oral. E encontramos reminiscências da estrutura narrativa em causa em nossos tempos, via figuras vocacionadas para o contar, como a personagem Dona Benta, proprietária do Sítio do Pica-pau Amarelo, de Monteiro Lobato, em Serões de Dona Benta (1937).
} 
Tal procedimento é bem característico dos autores românticos, que valorizam a oralidade e se permitem pular a tradição clássica, proclamando-se legítimos legatários dos trovadores medievais e contadores de histórias. Vejamos:

\begin{abstract}
Vós os que não credes em bruxas, nem em almas penadas, nem em tropelias de Satanás, assentai-vos aqui ao lar, bem juntos ao pé de mim, e contar-vos-ei a história de D. Diogo Lopes, senhor de Biscaia. E não me digam no fim: "não pode ser". Pois eu sei cá inventar coisas destas? Se a conto, é porque a li num livro muito velho. E o autor do livro velho leu-a algures ou ouviu-a, que é o mesmo, a algum jogral em seus cantares. É uma tradição veneranda; e quem descrê das tradições lá irá para onde o pague. Juro-vos que, se me negais esta certíssima história, sois dez vezes mais descridos do que $\mathrm{S}$. Tomé antes de ser grande santo. E não sei se eu estarei de ânimo de perdoar-vos como Cristo the perdoou. Silêncio profundíssimo; porque vou principiar. (HERCULANO, 1952, p. 17)
\end{abstract}

Outrossim, uma das expressões mais vivas dos primeiros brasileiros é o interesse pela Inconfidência Mineira enquanto parte do processo de autonomia nacional. De onde, na trajetória de nossa prosa de ficção, ser Joaquim Norberto um dos intelectuais que tentam "produzir no Brasil versões tupiniquins do projeto histórico-cultural de Alexandre Herculano" (DURIGAN, 1983, p. 36), defendendo a reforma romântica proposta por Gonçalves de Magalhães na revista Niterói (1836) e sendo um dos precursores do gênero romance, ao produzir obras como As duas órfãs (1841), escrever o "canto épico" A cabeça de Tiradentes (1861) e a História da Conjuração Mineira (1873).

Nesta esfera, o herculaniano Eurico, o presbitero, que relata os eventos mediante os quais o Estado luso se forma, bem como A barca dos amantes (1991), livro do premiado escritor brasileiro Antônio Barreto, que se apropria em tal narrativa de elementos do passado nacional e da biografia do árcade inconfidente Tomás Antônio Gonzaga, são dois romances históricos que ensejam uma comparação. Senão, vejamos:

\footnotetext{
A importância da Idade Média na literatura portuguesa se equipara à importância do Arcadismo e da Inconfidência Mineira na história da literatura brasileira. [...] Antonio Candido, naquilo que de mais polêmico há em Formação da literatura brasileira (1959), situa o início da construção da autonomia da literatura brasileira no Arcadismo. Do mesmo modo que a expulsão dos mouros dá origem à nação portuguesa, a Inconfidência Mineira, seus poetas, seus escritos dão origem à literatura brasileira. $\mathrm{O}$ aproveitamento da Inconfidência pela República e a transformação de seus participantes em heróis nacionais inserem o episódio tanto na série heroico-lendária quanto na série histórica propriamente dita. Tiradentes seria, nesta leitura, o herói antigo (aquele que expressa e carrega em si os valores do grupo), similar de Pelágio. Gonzaga seria já o herói individualista, principalmente no que diz respeito à facilidade de exteriorização de episódios da vida íntima, apesar de compartilhar, com Eurico e Tiradentes, alguns traços do herói antigo. (FRANÇA; SILVA, 2000, p. 288-289)
} 
Ainda em solo brasílico, assinalamos o caso do romântico José de Alencar. Acompanhando Eurico, o presbítero, o literato cearense publica o fragmento de romance Ex-homem (1877), em que se revela contrário ao celibato clerical. Ademais, o criador de $O$ Guarani, que tem, entre os escritores portugueses, Alexandre Herculano como “o príncipe de seus prosadores" (ALENCAR, 1993, s.n.), segue os passos do escritor de $O$ bobo no gênero que ele introduz em seu país, ou seja, o romance histórico.

Por sinal, $O$ Guarani, hoje agrupado entre os livros indianistas de José de Alencar, mas originalmente classificado, pelo próprio autor, como romance histórico, expõe um herói índio cujo código ético é semelhante, em tudo, ao do cavaleiro medieval, trabalhado por ficcionistas como Alexandre Herculano. E em 1865, a narrativa histórica no Brasil alcança o auge com As minas de prata (1864-1865), outra criação romanesca alencariana, anunciada no primeiro volume como "continuação de $O$ Guarani”. Neste ponto, é pertinente trazermos à baila que

Iracema: lenda do Ceará (1865), situada por José de Alencar na fase protohistórica do período orgânico da literatura brasileira (como Alexandre Herculano situa Eurico, o presbítero naquela parte da vida pública e privada dos séculos semibárbaros, que não cabe no quadro da história social e política) e que, apesar de não poder ser tomada como um romance histórico, por lhe faltarem ingredientes, guarda alguns traços da epopeia, possui Argumento Histórico, em que o seu autor fala da conquista do Ceará, de Martim Soares Moreno, de Antônio Filipe Camarão, o índio Poti, e acaba por ser tão histórica quanto algumas obras no gênero. (RIBEIRO, 1997, p. 943)

Com relação a José de Alencar, de igual maneira, devemos recordar que, na famosa polêmica travada entre ele e Gonçalves de Magalhães em torno de um poema deste último, A confederação dos Tamoios (1856), texto acerbamente criticado pelo criador de Iracema, o monarca de nosso Segundo Império, D. Pedro II, tomando o partido do bardo de Suspiros poéticos e saudades (1836), utiliza-se de

todo o seu poder para desmoralizar José de Alencar. Uma das tentativas que
não deram resultado foi a convocação de nada menos que Alexandre
Herculano para desfazer os males de José de Alencar através da avaliação a
ele pedida do poema de Gonçalves de Magalhães. A resposta de Alexandre
Herculano foi literária e não deu oportunidade de uso político.
(RODRIGUES, 2001, p. 135)

Eis aqui, de uma autobiografia imaginária do romancista de A Guerra dos Mascates (1871-1873), um comentário sobre o acontecido supracitado:

A mobilização do imperador atingiu níveis impensáveis, levando-o inclusive a se dirigir a Alexandre Herculano, grande escritor e historiador português, solicitando-lhe a apreciação da obra de Gonçalves de Magalhães. A resposta de Alexandre Herculano apenas confirmou a crítica, considerando o poema uma obra fracassada. (RODRIGUES, 2001, p. 30) 
Ainda sobre José de Alencar, mencionemos que a produção teatral dele, a exemplo do drama $O$ jesuíta (1875), representa outra demonstração do interesse pela modalidade genológica histórica por parte deste literato cearense, cujo conterrâneo Franklin Távora tem sua utilização de técnicas de ficção histórica abordadas, em Formação da literatura brasileira, por Antonio Candido, o qual percebe que,

no tratamento da matéria, Franklin Távora parece ter sofrido influência marcada de $O$ monge de Cister, através do qual emprega a técnica bifocal de Walter Scott (oscilação entre o plano inventado e o plano reconstituído). A tensão político-econômica entre senhores de engenho e comerciantes é descrita com um colorido, um tom muito próximo à tensão entre burguesia e nobreza, que Alexandre Herculano deu como pano-de-fundo às vinganças de Frei Vasco, no livro citado, e de Leonor Teles, em "Arras por foro de Espanha”, documentado nas páginas de Fernão Lopes. As tavernas dos mascates, onde se armam conluios por entre espias, parecem gêmeas das de Lisboa medieval, onde, naqueles livros, também se traçam planos de rebelião. Afinal de contas, o fenômeno histórico que ele transpôs para a ficção não deixava de apresentar semelhanças com o tratado por Franklin Távora: ascensão das camadas burguesas, amparadas no comércio, em detrimento dos latifúndios em decadência. E se no brasileiro não encontramos a mesma argúcia histórica, nem quadros tão ricos como a procissão dos mesteirais, em O monge de Cister, ou o ajuntamento da arraia-miúda, nas "Arras", não lhe poderemos negar consciência do problema traçado [...], nem algumas cenas de boa qualidade, sobretudo o excelente combate de Goiana, em $O$ matuto, de 1879. (CANDIDO, 1993, p. 272-273)

$\mathrm{O}$ igualmente brasileiro Casimiro de Abreu, poeta que chega a morar em

Portugal, lançando-se como prosador de ficção, escreve algumas narrativas, das quais sobressai o folhetim Carolina, publicado em 12 e 13 de março de 1856 no Progresso, jornal lisboeta. E sobre tal criação escrita, cujo interesse maior reside no trabalho de seu autor com as paixões avassaladoras, motivo literário que anteriormente recorre nas composições históricas de Alexandre Herculano e nas novelas do autor de $O$ arco de Sant'Ana (1845-1850), Almeida Garrett, nosso estudioso Soares Amora profere as palavras infracitadas:

O pequenino romance contém, facilmente perceptíveis, os comuns ingredientes dos romances passionais da época, já utilizados por Alexandre Herculano e por Almeida Garrett, e a partir de então muito empregados por Camilo Castelo Branco, José de Alencar, Bernardo Guimarães e o Visconde de Taunay. E ao falar de ingredientes dos romances passionais românticos refiro-me ainda à situação (como ocorre no mencionado Carolina) do amante que regressa para cumprir juramento de amor e é cientificado do ultraje de um sedutor (situação sobre a qual construiu Alexandre Herculano todo o drama de Frei Vasco, protagonista de $O$ monge de Cister; refiro-me ao tema da "coroa da virgindade" arrancada da fronte de inocente donzela, por cínico D. Juan, com todas as dolorosas consequências impostas pela sociedade à desgraçada; refiro-me ao tema da punição infalível do algoz, pela mão do amante vilipendiado e pela justiça divina; e refiro-me, finalmente, ao tema dos lenitivos da religião, que ensina o caminho do perdão, do esquecimento das lágrimas terrenas e da esperança de salvação. (AMORA, 1977, p. 168169) 
De nosso panorama oitocentista, cabe-nos também lembrar o prosador realistanaturalista Júlio Ribeiro, que estampa em folhetim uma narrativa épica a respeito da Guerra dos Emboabas e de um sacerdote jesuíta com marcante papel no processo de colonização de várias cidades do Brasil, em regiões que hoje correspondem a estados como o de São Paulo, Minas Gerais e Paraná. Estamos falando de um "romance histórico contra o celibato clerical, encenado no Brasil-Colônia, Padre Belchior de Pontes (1876-1877), obra em que se faz notar o eco de Eurico, o presbítero, de Alexandre Herculano" (MALARD, 1997, p. 792).

Nesta ambiência cultural, podemos referir que a primeira ficção científica da lavra de um brasileiro intitula-se Páginas da história do Brasil escrita no ano 2000, produção inacabada e publicada em forma de folhetim, de 1868 a 1862, no jornal republicano O Jequitinhonha, de Diamantina (MG), visando satirizar o imperador D. Pedro II e tendo por autor o responsável pela divulgação e cristalização da história e do mito de Chica da Silva no livro Memórias do distrito diamantino da comarca do Serro Frio (1868). Aludimos ao romancista e historiador Joaquim Felício dos Santos, para quem a coletânea de Alexandre Herculano Lendas e narrativas, conforme Alexandre Eulálio, “é o livro motor” (MIRANDA, 1995, p. 115).

Além do mais, o dito realista Machado de Assis, em sua severa e fina crítica a $O$ primo Basílio (1878), de Eça de Queirós, mostra ser um leitor da modalidade literária introduzida por Alexandre Herculano em vernáculo: a ficção histórica, ao aconselhar o escritor de Póvoa de Varzim a voltar "a beber aquelas águas sadias de $O$ monge de Cister, de $O$ arco de Sant'Ana e de $O$ Guarani" (ASSIS, 1992, p. 908). Aqui, cumprenos registrar a contribuição da vasta cultura letrada de uma figura lusa que, proveniente de uma família tradicional da Península Ibérica, vem da cidade do Porto para cuidar, no Brasil, de um irmão doente, segundo uns, ou para se restabelecer de uma desilusão amorosa, segundo outros. Estamos fazendo menção à esposa de Machado de Assis, irmã do poeta e jornalista lusitano Faustino Xavier de Novais, amiga de Camilo Castelo Branco e de outros escritores portugueses: Dona Carolina Augusta Xavier de Novais.

$\mathrm{Na}$ verdade, a vários títulos, o casamento é decisivo na vida do mestre brasileiro, que, por ser afrodescendente, sofre grande preconceito da parte dos irmãos da noiva: Miguel e Adelaide Xavier de Novais (Faustino, dono de $O$ Futuro, revista da qual o amado de Dona Carolina Augusta colabora em 1862, já se encontra falecido em 
decorrência de uma enfermidade, encefalite, causa dos distúrbios mentais do poeta). Apesar de tudo, no dia 12 de novembro de 1869, os dois apaixonados se casam no Cosme Velho, precisamente na capela particular da casa do Conde de São Mamede, Rodrigo Ferreira Felício, que auxilia a vinda de Faustino para o Brasil.

Após se tornar mulher do romancista de Dom Casmurro (1899), sua companheira carinhosa, refinada e ilustrada, Dona Carolina Augusta passa e ser também para ele uma espécie de secretária particular, a qual (quer a tradição) revisa, retifica e passa a limpo os textos do marido, ajudando-o a escrever, além de lhe despertar a leitura dos clássicos lusitanos, da língua inglesa e da Europa em geral, redefinindo para a maturidade o estilo de Machado de Assis, cuja imagem do Brasil, enquanto nação, extrapola o localismo. Por isto o fato de ele, ao contrário de outros autores oitocentistas daqui, não ser lusofóbico, para o que muito contribui o contato com sua esposa.

Nas narrativas da fase de maturidade estético-verbal do intelectual carioca, principalmente no romance Memórias póstumas de Brás Cubas (1881), em que o leitor aparece, digamos, na condição de personagem, ainda que com caracterização minimalista, o mesmo Machado de Assis adota a técnica ensaística, de caráter digressivo-conversacional, fragmentário e paródico, que tem raízes nos satiristas da Antiguidade, bem assim no pensamento do inglês John Locke, e que é utilizada por Alexandre Herculano em "O pároco de aldeia", história incluída em Lendas e narrativas, e por Almeida Garrett na novela Viagens na minha terra (1843).

O Alexandre Herculano de "O pároco de aldeia" e o Almeida Garrett das Viagens na minha terra seguem as passadas de Erasmo de Roterdã, François Rabelais, Denis Diderot, entre outros, presentificando uma célebre tradição humorística e irônica, o que confere a ambos os textos um aspecto extremamente peculiar na arte da palavra luso-brasileira. Até porque, inserindo-se também na linhagem de Miguel de Cervantes, o qual, no prefácio de Dom Quixote (1605), abre este livro dirigindo-se ao “desocupado leitor", as duas retromencionadas narrativas lusas levam nosso Machado de Assis à leitura de Viagem à roda de meu quarto (1794), do francês Xavier de Maistre, e este, por sua vez, à produção do irlandês Laurence Sterne, notadamente $A$ vida e as opiniões do cavalheiro Tristam Shandy (1760-1767).

Como podemos ver, "O pároco de aldeia" e Viagens na minha terra, sob a forma da narrativa-ensaio, que outorga elasticidade à ação ficcional, concorrem para o advento 
do romance moderno lusófono, no caso vertente, tanto em Portugal quanto no Brasil, pois, como bem afirma Antonio Candido em seu ensaio "O escritor e o público", integrante de Literatura e sociedade:

Uma boa parte da ficção moderna em prosa se elaborou graças aos arabescos da digressão, da intercalação, do retrospecto, do enredo secundário - que foram uma espécie de prova dos nove da capacidade narrativa. (CANDIDO 2000, p. 80)

Embora, na renovação literária oitocentista em língua portuguesa, Alexandre Herculano tenha a mesma relevância que Almeida Garrett, no tocante a este, que até parece dispor de maior prestígio acadêmico, é incrível e, ao mesmo tempo, lamentável, em nível de recepção mais ampla no Brasil, sua quase ausência. E atinente à inexpressiva acolhida do autor de $O$ arco de Sant'Ana no nosso país, em termos de grande público, é a anotação infracitada e elaborada por Soares Amora:

\begin{abstract}
Algumas vezes Almeida Garrett compareceu perante o público brasileiro em edições portuguesas que lograram razoável difusão; aqui e ali, provocou artigos, ensaios críticos e até mesmo teses universitárias; e o Frei Luís de Sousa mais de uma vez subiu à cena brasileira. Mas se isto é alguma coisa em matéria de presença, entre nós, de um escritor português, convenhamos em que tal presença não se compara com a que têm mantido, no Brasil, um Luís de Camões, um Alexandre Herculano, um Camilo Castelo Branco, um Júlio Dinis, um Eça de Queirós e, mais recentemente, um Fernando Pessoa. (AMORA, 1969, s.p.)
\end{abstract}

Particularmente, Alexandre Herculano, à sua época, é visto como uma lenda viva, dispondo, pela missão intelectual, de uma aura de devoção e alto respeito pouco vulgares em qualquer literatura. E no que tange à ampla recepção deste autor em termos de grande público, o filólogo Silveira Bueno declara, em nossa conjuntura históricocultural dos inícios da segunda metade do século XX, que

no Brasil Almeida Garrett está quase desconhecido enquanto Alexandre Herculano continua a ser lido e imitado por todos. Os seus assuntos estão nos moldes de nosso pendor romântico e desde os moços até os velhos, todos lemos e gostamos imensamente do Eurico, o presbítero, do Monge de Cister, de $O$ bobo e principalmente das Lendas e narrativas. (BUENO, 1965, p. 65)

Em Psicologia de Alexandre Herculano, já no alvorecer dos Novecentos em território brasílico, dentro de nossa literatura escolar, naquela época formulada a partir de excertos colhidos, sobretudo, na literatura portuguesa, quando esta não é utilizada diretamente, bem como dentro do contributo da instituição escola para forjar, nas 
mentalidades, a imagem do escritor grande homem, também o crítico literário brasileiro Liberato Bittencourt declara que

\begin{abstract}
todo o mundo que lê em português conhece Alexandre Herculano. Todos the admiram assim a superioridade da inteligência como a erudição literária e a profundidade do saber histórico. Não há uma só criança em colégio secundário, pelo menos no Brasil, que não conheça, por exemplo, "A morte do lidador". Cultor extremado da língua, das belezas sem par do lusitano idioma, um só não existe em terra brasileira que desconheça as Lendas $e$ narrativas ou $O$ bobo, o Eurico ou $O$ monge de Cister. (BITTENCOURT, s.d., p. 6)
\end{abstract}

Concluindo, julgamos que, com este artigo, realizamos uma abordagem, que se quer renovada, de uma das duas matrizes literárias portuguesas durante o período romântico, demonstrando que Alexandre Herculano, ao lado de Almeida Garrett, prepara o futuro literário em vernáculo, particularmente o luso-brasileiro, até por contribuir para o desenvolvimento da obra de ficcionistas da categoria de Machado de Assis.

\title{
REFERÊNCIAS
}

ALENCAR, J. O nosso cancioneiro. Campinas: Pontes, 1993.

AMORA, A. S. Apresentação. In: HERCULANO, A. O monge de Cister. Rio de Janeiro: Tecnoprint, s.d.

Propedêutica para os leitores de Herculano. Monumentos literários da língua portuguesa: Alexandre Herculano. São Paulo: Saraiva, 1969.

O romantismo. São Paulo: Cultrix, 1977.

de ASSIS, M. Obra completa. Rio de Janeiro: Nova Aguilar, 1992. Vol. 3.

BITTENCOURT, L. Psicologia de Alexandre Herculano. Rio de Janeiro: Francisco

Alves, 1913.

BOSI, A. História concisa da literatura brasileira. São Paulo: Cultrix, 1981.

BUENO, S. História da literatura luso-brasileira. São Paulo: Saraiva, 1965.

CANDIDO, A. O escritor e o público. Literatura e sociedade. São Paulo: Publifolha, 2000 .

Formação da literatura brasileira: momentos decisivos. Belo Horizonte:

Itatiaia, 1993. 
DURIGAN, J. A. Sete pontos insignificantes relacionados com a obra de Alexandre Herculano. Revista Estudos Portugueses e Africanos (EPA), Campinas, v. 1, n. 2, p. 36, novembro, 1983.

FRANÇA, C. T.; SILVA, C. I. O que separa os amantes? Uma leitura comparativa de Eurico, o presbítero, de Alexandre Herculano, e A barca dos amantes, de Antônio Barreto. In: BOECHAT, M. C. et al. (Orgs.). Romance histórico: recorrências e transformações. Belo Horizonte: FALE/UFMG, 2000.

GUIMARÃES, B. Histórias e tradições da província de Minas Gerais. São Paulo: Cultrix, 1976.

HERCULANO, A. Lendas e narrativas. São Paulo: W.M. Jackson, 1952.

JOLLES, A. Formas simples. São Paulo: Cultrix, 1997.

LAJOLO, M.; ZILBERMAN, R. A leitura rarefeita: livro e literatura no Brasil. São Paulo: Brasiliense, 1991.

MALARD, L. Alexandre Herculano e a literatura brasileira. Cadernos do Centro de Pesquisas Literárias da PUCRS, Porto Alegre, v. 1, n. 2, p. 29, junho, 1995. Júlio Ribeiro. Biblos: enciclopédia Verbo das literaturas de língua portuguesa. Lisboa: Verbo, 1997.

MIRANDA, W. M. A aventura europeia de Alexandre Herculano. In: A trama do arquivo. Belo Horizonte: Editora UFMG, 1995.

MOISÉS, M. Jogral. In: Dicionário de termos literários. São Paulo: Cultrix, 1997, p. 297.

MONTELLO, J. Apresentação. In: HERCULANO, A. O bobo. Rio de Janeiro: Tecnoprint, s.d.

RIBEIRO, M. A. Romance histórico II. Biblos: enciclopédia verbo das literaturas de língua portuguesa. Lisboa: Verbo, 1997.

RODRIGUES, A. E. M. As polêmicas. In: José de Alencar: o poeta armado do século XIX. Rio de Janeiro: Fundação Getúlio Vargas, 2001.

VIEIRA, N. H. Brasil e Portugal: a imagem recíproca (o mito e a realidade na expressão literária). Lisboa: Ministério da Educação/Instituto de Cultura e Língua Portuguesa, 1991.

VOLOBUEF, K. Frestas e arestas: a prosa de ficção do romantismo na Alemanha e no Brasil. São Paulo: UNESP, 1999. 